\title{
Nostril selection influences the success rate of nasogastric tube insertion; A prospective randomized study
}

Volume 7 Issue I - 2017

\section{Introduction}

Nasogastric tube (NGT) placement in a paralyzed, intubated patient is a challenging task with failure rate of $50-66 \%$ on first attempt. ${ }^{1-3}$ In a testimony to the difficulty faced in seemingly innocuous procedure, literature is replete with mention of Maneuvers like Reverse Sellick maneuver, flexion of head, SORT maneuver (Sniffing position, NGT orientation, contralateral rotation and twisting movement), and use of a 'gloved finger' to steer the NGT. ${ }^{4-6}$ Literature also mentions use of variety of contraptions like flexible nasoendoscope, intubating stylet, glidescope and uretral guide wire as a stylet for NGT insertion. ${ }^{7-10}$ Perhaps the reason lies in radiological evidence for esophagus not aligned in midline in majority. ${ }^{11,12}$ We therefore hypothesized difference in success at NGT insertion between right and left nostril and that upon failure of initial attempt, changing the nostril should lead to successful NGT insertion in a paralyzed and intubated patient.

\section{Methods}

The study was approved by the institute's ethical committee. Patient posted for elective surgery requiring NGT insertion were included. General Anaesthesia was standardized with induction using injection Propofol and maintenance of anaestheia using inhalational anaesthetic agent, Isoflurane in Oxygen. Neuromuscular blockade for endotracheal intubation and for surgical paralysis was achieved using injection Vecuronium Bromide which was reversed at the end of surgery using premixed injection Neostigmine with Glycopyrolate. All patients received antiemetic prophylaxis using Injection Ondansetron. Analgesia was ensured using Injection Fentanyl and Injection Paracetamol. Anaesthesia was provided by consultant anaesthesiologists, each with more than 10 years of work experience. Patients with upper airway deformity like deviated nasal septum and patients with perceived difficult intubation and coagulopathy were not included. Poor visualization of glottis opening upon direct laryngoscopy and resistance at level of posterior nares led to exclusion.

Patient's head was kept in neutral position using an adequate size silicon head-rest. Nostrils were lubricated. Using random number table, primary attempt at NGT insertion was decided for either right or left nostril. NGT (16G) was smeared with lubricating gel. On failure to advance NGT beyond hypopharynx, insertion through other nostril was attempted. Upon failure of secondary attempt maneuvers as deemed appropriate were used. Intragastric placement of NGT was confirmed by the Bubble Test and by aspiration of gastric fluid whenever possible. Outcome of each attempt was recorded. Assuming a $50 \%$ failure rate in the first attempt and $50 \%$ of the failures of the first attempt would succeed upon change of the nostril, 96 patients were required for the right and the left nostril each, for results to be statistically significant with a power of $90 \%$ and a level of confidence of $5 \%$.

\author{
Manish Tandon, Mandeep Dhankhar,Vijay \\ Kant Pandey, Sunaina Tejpal Karna, Chandra \\ kant Pandey, Priyanka Jain \\ Institute of Liver and Biliary Sciences, India
}

Correspondence: Manish Tandon, Associate Professor Anaesthesia, Institute of Liver \& Biliary Sciences, D- I,Vasant kunj, New Delhi, India, Tel 9|987|437478, Fax +9| I |463000 I0, Email manishtandon25@rediffmail.com

Received: October 27, 2016 | Published: January 03, 2017

\section{Statistical analysis}

Data was analyzed using SPSS Version 21.0. For categorical variables, Chi Square test was used to test statistically significant difference. McNemar's two sample test was used to check for statistical significance of outcome in second attempt on failure of the first attempt. P value less than 0.05 was considered statistically significant.

\section{Results}

Two hundred and thirty eight patients were considered eligible for inclusion. Forty six patients were excluded due to difficulty in passing NGT beyond posterior nares. No patient was excluded because of poor visualization of larynx upon laryngoscopy. Ninety six primary NGT placements were attempted through each nostril (CONSORT Flow chart). Demography of the patient population in either group was comparable (Table 1). Primary attempt was successful in 137 out of 192 patients (71\%) (Table 2). Primary attempt was successful through right nostril in 66\% (63/96) and through left nostril in $77 \%$ (74/96) patients $(\mathrm{P}<0.0001)$ (Table 2).

Secondary attempt was successful in 64\% (14/33) through right nostril and in 58\% (19/33) patients through left nostril $(\mathrm{P}<0.0001)$ (Table 2). Placement of NGT by change of nostril was successful in 33 out of 55 secondary attempts $(60 \%)(\mathrm{P}<0.0001)$ (Table 2). Out of these 55 secondary attempts, 22 were through right nostril of which 14 were successful (64\%) and 33 were through left nostril of which 19 (58\%) were successful. Twenty two out of 192 patients (12\%) required additional maneuvers $(\mathrm{P}<0.0001)$ (Table 2). Total attempts (primary plus secondary) through right nostril were 118 out which 77 (65\%) were successful. There were 129 attempts through left nostril, out of which $93(72 \%)$ were successful $(\mathrm{P}<0.0001)$ (Table 2). 


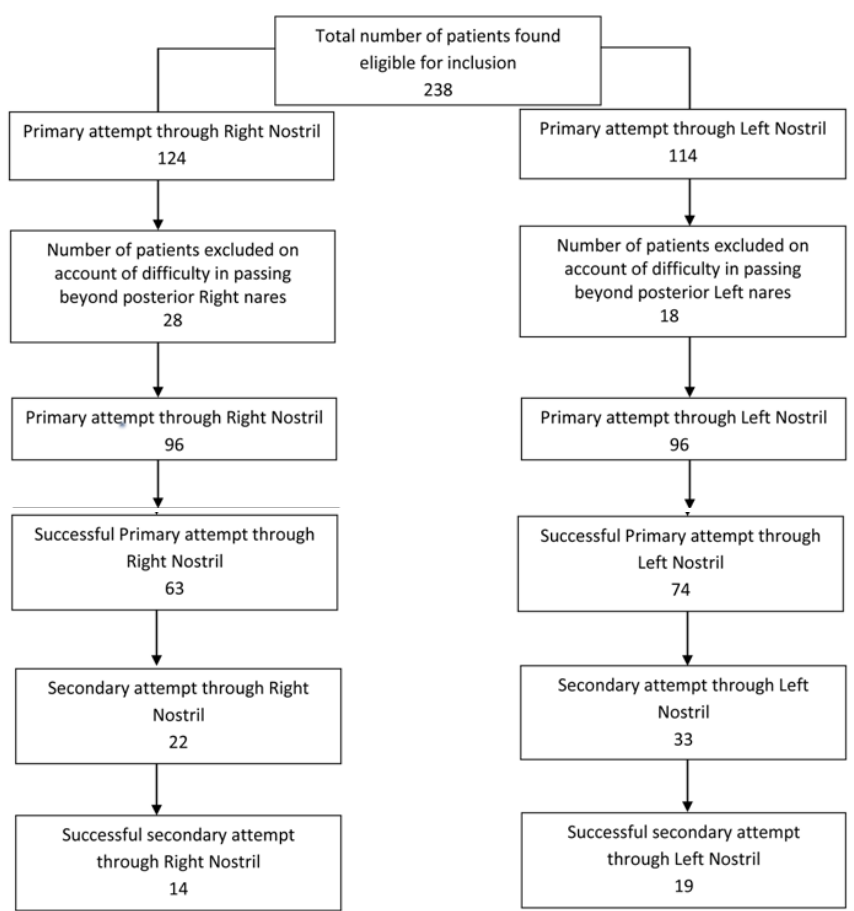

\section{Discussion}

In this study, we found statistically significant difference in success of NGT insertion between right and left nostril and that change of nostril is a simple and effective maneuver. In our study, failure at NGT insertion in first attempt was 29\% (55 out of 192) and on change of nostril was $40 \%$ (22 out of 55) against the reported failure rate of $50-60 \% .{ }^{1,2}$ Change of nostril led to successful NGT placement in 33 out of 55 failures (60\%) of first attempt. It is believed that esophageal opening is midline. Smith et al. demonstrated laterally displaced Table I Demographic Profile of study population (Mean \pm SD) esophagus in $49 \%$ of subjects of which $92 \%$ were displaced to left and $8 \%$ were displaced to right of midline. ${ }^{11}$ Another study found that esophagus was displaced in $52.6 \%$ of subjects with most displacements to left and the incidence of lateral displacement of esophagus further increased to $90.5 \%$ on application of cricoid pressure. ${ }^{12}$ We found statistically significant difference in the success rate at NGT insertion between the two nostrils during primary and secondary attempt as well. This is possibly because in the studied population, either of the nostril is better aligned with the esophagus which is not in midline and is deviated to either side of midline.

Benkhadra et al. ${ }^{13}$ found left and right displacement of esophagus in $61.5 \%$ and $23 \%$ upon both flexion as well as extension of the neck, a maneuver commonly employed for NGT insertion. ${ }^{13,5}$ In the same study Benkhadra et al. ${ }^{13}$ concluded that $92 \%$ of the subjects have lateral displacement of esophagus in the neutral position of the head. We found cumulative success rate of $89 \%$ at insertion of the NGT through either nostril (170 out of 192 patients) with head placed in neutral position, which could possibly be due to equal percentage (89\%) of the study population having lateral displacement of the esophagus in the neutral position of head with a cuffed endotracheal tube in situ such that either of the nostril which is in better alignment with the laterally displaced esophagus lead to successful NGT insertion.

In our study population, significant difference at success in NGT insertion was observed between the right and the left nostrils during primary, secondary and all attempts put together. This is supports our hypothesis that either of the nostrils is better aligned with the esophageal opening and therefore $60 \%$ of failures of primary attempt of NGT insertion succeeded only by change of nostril. Out of 192 patients, overall NGT placement was successful via left nostril in 93 patients (48\%), and through right nostril in 77 patients (40\%). In 22 patients $(12 \%)$, NGT could not be placed through both nostril and required additional maneuvers. This may be interpreted for the study population as orientation of esophagus towards left of midline in $48 \%$ and towards right of midline in $40 \%$.

\begin{tabular}{lll}
\hline Measurement & Right nostril & Left nostril \\
\hline Height $(\mathrm{cms})$ & $163.3 \pm 9.3$ & $162.1 \pm 8.7$ \\
Weight $(\mathrm{kgs})$ & $63.6 \pm 12.8$ & $65.1 \pm 13.0$ \\
BMl $(\mathrm{kg} / \mathrm{m} 2)$ & $23.8 \pm 4.1$ & $24.7 \pm 4.6$ \\
\hline
\end{tabular}

Table 2 Success and Failure rates of primary and secondary attempts through either nostril

\begin{tabular}{llllllll}
\hline & $\begin{array}{l}\text { Primary } \\
\text { attempt }\end{array}$ & $\begin{array}{l}\text { Secondary } \\
\text { attempt }\end{array}$ & $\begin{array}{l}\text { Total } \\
\text { attempt }\end{array}$ & $\begin{array}{l}\text { Primary } \\
\text { successful } \\
\text { attempt }\end{array}$ & $\begin{array}{l}\text { Secondary } \\
\text { successful } \\
\text { attempt }\end{array}$ & $\begin{array}{l}\text { Total successful } \\
\text { attempt }\end{array}$ & $\begin{array}{l}\text { Failed } \\
\text { attempts }\end{array}$ \\
\hline Right nostril & 96 & 22 & 118 & $63 / 96(66 \%)$ & $14 / 22(64 \%)$ & $77 / 118(65 \%)$ & 8 \\
Left nostril & 96 & 33 & 129 & $74 / 96(77 \%)$ & $19 / 33(58 \%)$ & $93 / 129(72 \%)$ & 14 \\
Total & 192 & 55 & 247 & $137 / 192(71 \%)$ & $33 / 55(60 \%)$ & $170 / 247(68 \%)$ & $22 / 192(12 \%)$ \\
\hline
\end{tabular}

In this study significantly more successful attempts at NGT insertion were through left nostril. Primary and secondary attempts put together, success rate was $72 \%$ (93 out of 129) for the left nostril, and was $65 \%$ (77 out of 118$)$ for the right nostril. $(\mathrm{P}<0.0001)$ This difference in the success rate is also in agreement with the findings of Smith et al. ${ }^{12}$ and is probably because left nostril is better aligned for NGT insertion than the right nostril.. ${ }^{11,12}$.

\section{Conclusion}

In a given population either of the nostrils could be better aligned with esophageal opening and therefore upon initial failure at insertion of the NGT, change of nostril is a simple and effective maneuver that may lead to successful placement of NG tube. In our study population, left nostril appears to be better aligned with esophageal opening and therefore left nostril should be the first choice for NGT placement.

\section{Conflicts of interest}

There is no conflict of interest.

\section{Acknowledgements}

None. 


\section{Funding}

None.

\section{References}

1. Mahajan R, Gupta R. Another method to assist nasogastric tube insertion. Can J Anaesth. 2005;52(6):652-653.

2. Appukutty J, Shroff PP. Nasogastric tube insertion using different techniques in anesthetized patients: a prospective, randomized study. Anesth Analg. 2009;109(3):832-835.

3. Mandal MC, Dolai S, Ghosh S, et al. Comparison of four techniques of nasogastric tube insertion in anaesthetized intubated patients: A randomized controlled trial. Indian J Anaesth. 2014;58(6):714-718.

4. Parris WC. Reverse Sellick maneuver. Anesth Analg. 1989;68(3):413423.

5. Mahajan R, Gupta R. Another method to assist nasogastric tube insertion. Can J Anaesth. 2005;52(6):652-653.

6. Najafi M, Golzari SE. SORT maneuver for nasogastric tube insertion. Anaesthesia. 2016;71(3):351.
7. Der Kureghian J, Kumar S, Jani P. Nasogastric tube insertion in difficult cases with the aid of a flexible nasendoscope. J Laryngol Otol. 2011;125(9):962-964.

8. Tsai YF, Luo CF, Illias A, et al.Nasogastric tube insertion in anesthetized and intubated patients: a new and reliable method. BMC Gastroenterol. 2012;12:99.

9. Moharari RS, Fallah AH, Khajavi MR, et al. The GlideScope facilitates nasogastric tube insertion: A randomized clinical trial. Anesth Analg. 2010;110(1):115-118.

10. Mahajan R, Gupta R, Sharma A. Insertion of a nasogastric tube using a modified ureteric guide wire. J Clin Anesth. 2009;21(5):387-388.

11. Smith KJ, Ladak S, Choi PT, et al. The cricoid cartilage and the esophagus are not aligned in close to half of adult patients. Can J Anaesth. 2002;49(5):503-507.

12. Smith KJ, Dobranowski J, Yip G, et al. Cricoid pressure displaces the esophagus: an observational study using magnetic resonance imaging. Anesthesiology. 2003;99(1):60-64.

13. Benkhadra M, Lenfant F, Bry J, et al. Cricoid cartilage and esophagus: CT scan study of the dynamic variability of their relative positions. Surg Radiol Anat. 2009;31(7):537-543. 